\title{
"Riding the waves of culture: an empirical study on acclimatization of expatriates in IT industry"
}

Raghavendra A. N. (D https://orcid.org/0000-0003-2147-4742

AUTHORS

R http://www.researcherid.com/rid/L-1545-2017

A. Shivakanth Shetty (D https://orcid.org/0000-0002-6826-4833

R http://www.researcherid.com/rid/F-5763-2018

ARTICLE INFO

Raghavendra A. N. and A. Shivakanth Shetty (2018). Riding the waves of culture: an empirical study on acclimatization of expatriates in IT industry. Problems and Perspectives in Management, 16(3), 432-442. doi:10.21511/ppm.16(3).2018.34

DOI http://dx.doi.org/10.21511/ppm.16(3).2018.34

RELEASED ON

Monday, 17 September 2018

RECEIVED ON

Tuesday, 06 March 2018

ACCEPTED ON

Monday, 03 September 2018

\section{(cc) EY-NG}

LICENSE

This work is licensed under a Creative Commons Attribution-NonCommercial 4.0 International License

JOURNAL

"Problems and Perspectives in Management"

ISSN PRINT $1727-7051$

ISSN ONLINE $1810-5467$

PUBLISHER

LLC "Consulting Publishing Company "Business Perspectives"

FOUNDER

LLC "Consulting Publishing Company "Business Perspectives"

NUMBER OF REFERENCES

33
NUMBER OF FIGURES

1
NUMBER OF TABLES

6

(C) The author(s) 2023. This publication is an open access article. 


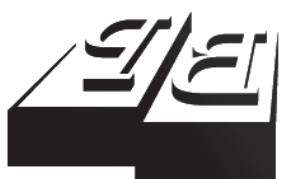

BUSINESS PERSPECTIVES

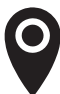

LLC "CPC "Business Perspectives" Hryhorii Skovoroda lane, 10, Sumy, 40022, Ukraine

www.businessperspectives.org

Received on: $6^{\text {th }}$ of March, 2018 Accepted on: $3^{\text {rd }}$ of September, 2018

(c) Raghavendra A. N., A. Shivakanth Shetty, 2018

Raghavendra A. N., Dr., Associate Professor, Department of Management Studies, Christ University, India.

A. Shivakanth Shetty, Dr., Associate Professor, Institute of Management, Christ University, India.
RIDING THE WAVES

\section{OF CULTURE: AN EMPIRICAL STUDY ON ACCLIMATIZATION OF EXPATRIATES IN IT INDUSTRY}

\begin{abstract}
The forces of globalization and subsequent trade across the borders have necessitated the firms to have their presence across the globe to meet the needs of their customers. The employees or expatriates will be sent on assignment to different countries for a period of time ranging from few weeks, months to years. This sudden exposure to the different environment not only makes these expatriates vulnerable to cultural shocks, but also may significantly affect their job performance. Their failure to acclimatize to the foreign conditions will not only hurt the confidence, career and life of the expatriate, but it will also cost a lot to the company. The present paper aims to understand of the process of expatriate adjustment in the Indian Information Technology (IT) industry by examining demographic variables and few organizational variables of expatriate's adjustment process. A structured questionnaire was distributed to the expatriate employees working in 50 IT companies in the Silicon city, Bengaluru. The study uses Chi-square test and linear regression for testing the hypotheses and found that there is a significant influence of demographic variables like gender, work experience and length of assignment on acclimatization of expatriates to their host country culture. The findings of the study proved that there is a significant relationship between demographic variables and the cultural acceptance of the expatriates. Hence, it is suggested that multinational companies should create an enabling environment within the organizations to make international assignees compatible and comfortable with different cultural values and inculcate cultural acceptance to make them successful in their international assignments.
\end{abstract}

\section{Keywords}

\section{JEL Classification}

\section{career support practices}

J26, M16, M54

\section{INTRODUCTION}

As the involvement of organizations in the international market increased, they are facing new human resource challenges and crisis, which are different from their conventional domestic human resource management. Business exposure to the global market and overseas assignments require executives and managers who can effortlessly mingle and operate successfully in different socio-cultural and environmental scenarios. But their success in overseas assignments has been tied down to their ability to deal with different socio-cultural background in host countries. Their inability to manage and cope with the different socio-cultural surroundings may result in stress, anxiety and radical decline in their job performance. Many of the empirical studies conducted on the subject report that when compared to the expatriates who adjust better, maladjusted expatriates' performances have been found to be well below the expected levels and hence are more likely to be withdrawn from their assignments before its completion (Caligiuri, 1997; Shaffer \& Harrison, 1998). The negative results have an impact on the business firms in terms of its performance and in- 
vestment. It has always been a major challenge for the employees to work in a culturally different environment. Inability to speak the local language, lack of cultural knowledge, and the obstacles faced by the self and the spouse to adjust to the new culture are some of the important causes of the failure of expatriates (Briscoe \& Sculer, 2004; Dowling \& Welch, 2005). In order to avoid such issues related to human capital management in the multinational corporations, the researcher conducted an empirical study on the expatriates working in Indian IT industry (geographically limited to Bangalore region) to answer the following questions:

1. What are the demographical variables that affect the acclimatization of expatriates in the Indian IT industry?

2. What is the current condition of expatriates with respect to the acclimatization period across the IT companies in Bangalore?

3. How do career support practices influence the expatriates in adjusting to the work environment of the host country?

A literature review focusing on the key concept of "acclimatization of expatriates" that includes the reasons for expatriation and the expatriate adjustment cycle and then explains the factors that can facilitate rapid expatriate adjustment to the host country culture was conducted. The term 'host country' in the present report refers to India, as the study was conducted on expatriates working in Bangalore, a city in the state of Karnataka in India. The findings of the empirical study based on online survey using structured questionnaire on the "Acclimatization of Expatriates" was presented, followed by a detailed explanation of the key factors that influence the initial expatriate adjustment to the host country culture. Based on the study results, suitable suggestions were provided to the IT industry to facilitate rapid acclimatization of expatriates.

\section{LITERATURE REVIEW}

Studies on expatriates are relatively new and have received wider attention and interest of both academicians and researchers across the world. The concept of expatriate family cross-cultural adjustment was introduced by Cleveland, Mangone, and Adams (1960) while examining the challenges faced by the families residing in foreign nations. Hays (1974) later investigated the various factors that contributed to the success and failure of international assignees and concluded that their work performance depended greatly on whether they were married and with a family or not. The main reason for the adoption of expatriates by different countries is to gain from their technical expertise, management development and organizational development (Edstrom \& Galbraith, 1977). Sometimes expatriates were sent as a liaison to bridge the gap between the foreign subsidiary and its headquarters based in a home country (Kobrin, 1988). Likewise, job factors, relational dimension, motivational state, marriage and family, and language skills were found to influence the job performance and success of an expatriate
(Ronen, 1989). Expatriates are not only the vital cogs in the growth and development of multinational companies, but also are of individual value to the organization they work (Carpenter, Sanders, \& Gregersen, 2001). Although the overseas assignments accomplished by the expatriates are of great value for the companies, it has to be borne in mind that the complex nature of expatriate assignments may result in the expatriates not being able to meet the programs goals. Studies show that failure rates associated with expatriate assignments are between 25\% and 40\% (Sanchez, 2000). The cost of a single failed expatriate assignment ranges between $\$ 250,000$ and $\$ 1,000,000$ (Vogel, Van Vuuren, \& Millard, 2008).

These overseas assignments may fail due to an earlier return of the expatriate, inability to achieve assignment objectives, subpar performance and host country problems (Cendant, 2001). The costs of expatriate failure in a host country may result in disrupted relationships with host country nationals, waste of recruitment, training and replacement cost, revenue losses due to subpar performance, reduced morale and damage to the 
brand equity of the company (Bhaskar-Shrinivas et al., 2005). On the other hand, failed overseas assignments may affect their physical and mental health, lower their self-esteem and result in loss of respect among colleagues. Overseas assignment failures can also result in family problems, loss of promotion opportunities and career growth (Shaffer et al., 2006). DeLollis (2007) reported that expatriates "go through an emotional cycle and typically hit a low between six and twelve months after starting an assignment". Personal factors are strongly related to an individual's values, beliefs, expectations and cultural background and have an impact on the employee's capability to adjust to a new environment and to condition their reactions to external stimuli (Erbacher, D'Netto, \& España, 2006). The empirical evidences available across the world reveal the fact that expatriate failure rate has been in the range of $10 \%$ to $80 \%$ and it may cost U.S. $\$ 40,000$ to U.S. $\$ 1$ million for each failed assignment (Hawley, 2009; Vogel \& van Vuuren, 2008). Irrespective of their rate of failure, expatriates are still considered very crucial for the long-term growth and development of multinational organizations (Reiche et al., 2011).

From the review of the above literature, it could be observed that a lot of research has been carried out on various aspects of expatriates like their selection, training and development, retention and replacement; however, very little research has been carried out on expatriate's acclimatization in the host countries. Further, the existing studies on the acclimatization of expatriates have been carried out in the context of Western countries. In order to advance the research on expatriate adjustment and acclimatization, additional research from a non-Western context like India is needed. This study is an attempt to fill that gap and to increase our understanding of expatriate's acclimatization in IT industry in India.

\section{METHODOLOGY}

The participants of the study were employed in 50 different IT companies situated in Bangalore, Karnataka. Only the expatriate employees were sent a survey questionnaire along with two reminders to optimize the response rate. However, out of the 500 survey mails sent, only 300 responses were received accounting for a response rate of $60 \%$. The study sample represented expatriates of 42 nationalities as shown in Table 1 . A majority of the respondents were from Australia and the United States.

Table 1. Number of expatriates from each nationality

Source: Survey data.

\begin{tabular}{|c|c|c|c|}
\hline Country & No. of expatriates & Country & No. of expatriates \\
\hline Argentina & 2 & Mozambique & 4 \\
\hline Australia & 30 & Netherlands & 8 \\
\hline Austria & 3 & New Zealand & 4 \\
\hline Bangladesh & 4 & Nicaragua & 4 \\
\hline Brazil & 4 & Philippines & 3 \\
\hline Canada & 3 & Poland & 1 \\
\hline China & 22 & Romania & 1 \\
\hline Colombia & 5 & Russia & 1 \\
\hline Cuba & 6 & Saudi Arabia & 2 \\
\hline El Salvador & 2 & Singapore & 9 \\
\hline France & 21 & South Africa & 2 \\
\hline Germany & 15 & Spain & 8 \\
\hline Indonesia & 14 & Taiwan & 3 \\
\hline Iran & 8 & Tanzania & 1 \\
\hline Italy & 13 & Thailand & 3 \\
\hline Japan & 17 & Turkey & 1 \\
\hline Lesotho & 2 & Ukraine & 2 \\
\hline Lithuania & 1 & United Kingdom & 12 \\
\hline Malaysia & 15 & United States & 30 \\
\hline Mexico & 9 & Uruguay & 1 \\
\hline Morocco & 3 & Vietnam & 1 \\
\hline
\end{tabular}




\subsection{Sampling}

Among a total of 300 expatriate respondents, 34\% were female respondents. The average work experience of the sample respondents was 8.5 years. Around one-third of the respondents were sent on at least one previous international assignment earlier, while around $30 \%$ of respondents had completed two or three assignments prior to their present assignment.

The questionnaire used for the study was developed after an extensive review of relevant literature. Likert scale type of questions were framed after an objective review of literature, so that they describe the study variables accurately. The questionnaire consisted of AA questions in total with $\mathrm{BB}$ questions for each variable.

A pilot study was conducted with 40 respondents before going for the main data collection and they were requested to scrutinize the questions and make suitable suggestions. The responses of the pilot study were discussed with a group of three consultants in order improve the questions. The questionnaire was thus corrected by eliminating the sensitive, redundant and leading questions.

\subsection{Theoretical framework}

A theoretical framework has been developed to assess the role of three important factors on expatriate's acclimatization, i.e., demographic factors, work related factors and organizational factors. Each of the above factor is further divided into five major independent variables, i.e., demographic factors are subdivided into gender of the expa- triates and their work experience; work-related factors are divided into area of work or sector and the length of the assignment in the host country and organizational factor is divided is assumed to be made up of the career support services provided by their employers. The impact of each of these five variables on the time taken by the expatriates to acclimatize in the host country, i.e., the dependent variables is subsequently analyzed.

The theoretical framework of the study is derived from different studies dealing with factors impacting expatriate acclimatization and general observations made by the researcher. Relationship between the variables can be shown diagrammatically as follows:

Further, based on the theoretical framework of the study, five hypotheses were developed. Hypotheses development was preceded by a thorough review of literature, which has been briefed in the following paragraphs.

First and foremost, the dependent variable, i.e., acclimatization of the expatriates was measured as the time taken by the expatriates to adjust and familiarize with the new job and work environment.

The hypotheses of the study were developed after a detailed review of past literature regarding expatriate acclimatization. There are no studies dealing with the role of gender in acclimatization; however, in the course of the informal conversations the researcher had with the respondents of the study, it was noticed that most of them were of the opinion that the time taken by expatriates to adjust to the host country workplaces was the same for men

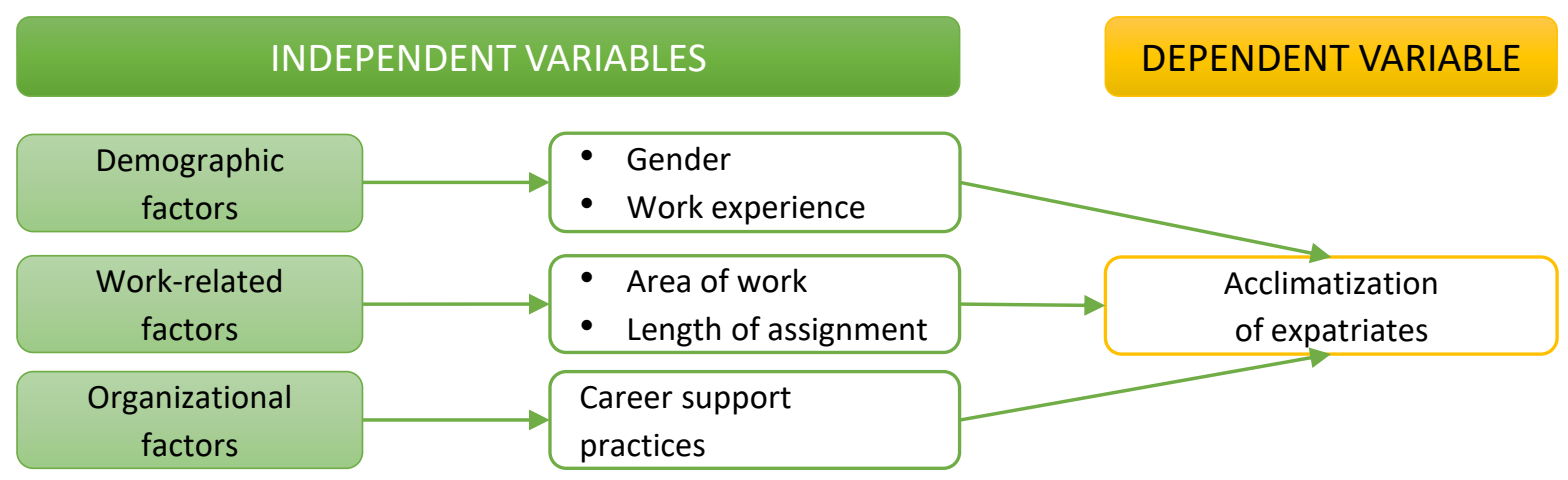

Figure 1. Dependent and independent variables 
and women, but there were no academic literature to justify this claim. On the basis of these observations and in order to fill the gap of gender-based acclimatization studies, Hypothesis 1 of the study was developed, which stated that the host country acclimatization of the expatriates does not depend on their gender.

Further, a limited number of empirical studies have found work experience to have a considerable impact on the rate at which expatriates adjust to their overseas workplace. Selmer (2002) examined the significance of international experience in facilitating expatriate adjustment, wherein it was found that expatriates who have prior experience adjust better to their overseas workplaces. Similarly, Merilainen (2008) found that, i.e., the international work experience of the expatriates enhanced their adjustment to the host country. However, as international experience does not essentially mean experience in the job role per se, it cannot be clearly said that work experience impacts acclimatization. Besides, there was also a limitation of studies that directly dealt with the role of on job experience in employee adjustment as most studies focused on job performance. In the backdrop of this dichotomy, the researcher developed Hypothesis 2, which posited that work experience did not have any impact on the rate at which expatriates acclimatize.

Similarly, area of work or the sector has also been found to impact expatriate adjustment in some studies. For instance, a study by Geetika and Gupta (2012) confirmed that the job role or the area of work of expatriates influences the rate at which they adjust to their overseas employment. Further, Kitler et al. (2011) also opined that expatriates with clarity regarding their job role adjust to their overseas workplaces better. However, the author realized a dearth of studies that examine the impact of sector of work on expatriate adjustment. Therefore, Hypothesis 3 was framed, which states that the host country acclimatization of expatriates is significantly impacted their area of work.

Similarly, the duration of overseas projects was also found to exert influence on the acclimatization of expatriates, albeit in a few studies. A study by Bonache (2005) confirmed that the duration of overseas assignments was one of the factors which impacted the expatriates' performance resulting in an intention to stay longer, i.e., adjustment. Similarly, Moulik, and Mazumdar (2012) also found that once expatriates get adjusted to the host country working environment, it becomes difficult for them to readjust to their parent workplace and suggested that by adopting rotation of employees on international projects, parent organizations can ensure ease of readjustment. However, as there was a limitation of studies that explicitly dealt with duration of assignment and adjustment, the researcher framed Hypothesis 4, which posited that the host country acclimatization of expatriates has significantly influenced the length of their assignment overseas.

Further, the expatriates' perceptions regarding the career support practices provided by the organization were found to reduce their intentions to leave the job and improve their performance in the organization (van der Heijden, van Engen, \& Paauwe, 2009; Stahl et al., 2009; Lazarova \& Caligiuri, 2001), which would naturally mean they are acclimatized. On similar lines, Geetika and Gupta (2012) found organizational support impacted expatriates' adjustment to host country workplaces positively. This lead to the development of the fifth and the last hypothesis of the study, i.e., Hypothesis 5, which states that career support practices have a significant impact on the acclimatization of expatriates. The hypotheses of the present study are as follows:

H1: Acclimatization of expatriates in the host country does not depend on their gender.

H2: Acclimatization of expatriates in the host country does not depend on their work experience.

H3: The acclimatization of expatriates in the host country is significantly influenced by the area of work.

H4: The acclimatization of expatriates in the host country is significantly influenced by the length of assignment.

H5: Career support practices have a positive influence on acclimatization of expatriates. 


\section{RESULTS AND DISCUSSION}

The study used Chi-square test to analyze the impact of gender and work experience on acclimatization of expatriates in the host country ( $\mathrm{H} 1$ and $H 2$ ). Further, linear regression was used to test the other hypotheses of the study, i.e., the influence of area of work on acclimatization of expatriates (H3); the influence of length of assignment on acclimatization of expatriates (H4); and the influence of career support practices on acclimatization of expatriates in the host country (H5). The results of the hypotheses testing are presented in the ensuing section.

H1: Acclimatization of expatriates in the host country does not depend on their gender.

It can be seen from Table 2 that there is no significant difference in the time taken by male and female expatriates to acclimatize and a majority of both male and female employees took 10 to 15 days to adjust.. It was also observed from that there is no statistically significant association between gender and the time taken by the expatriates to acclimatize [ $p$-value $(0.459)>0.05]$. Therefore, it can be inferred from the table that both male and female expatriates needed almost the same duration to acclimatize in the host country. The qual- ity of in-house training given in the multinational corporations (MNCs) to prepare employees for the overseas assignments also played a major role in reducing the gender difference in the process of acclimatization. Hence, Hypothesis 1 is accepted.

It is interesting to note that the male and female expatriates take the same time to adjust to a host country, as it contradicts the notion that women find it difficult to acclimatize. However, no studies were found to provide a literary backup to this finding. This hypothesis was formed on the basis of the inputs obtained by the researcher from the study area while making impromptu conversations with employees of various MNCs while administering the questionnaire.

H2: Acclimatization of expatriates in the host country does not depend on their work experience.

The study included people with less than two to more than fourteen years of work experience. It can be seen in Table 3 that work experience of the expatriates has a significant influence on their adjustment in the host country. It can be seen from is also clear that there is a significant correlation between the work experience and the time taken to acclimatize. Higher the work experience, less-

Table 2. Cross tabulation between gender and acclimatization period

\begin{tabular}{|c|c|c|c|c|c|c|c|}
\hline \multirow{2}{*}{ Gender } & \multicolumn{6}{|c|}{ Acclimatization period (in days) } & \multirow{2}{*}{ Total } \\
\hline & $<5$ & $5-10$ & $10-15$ & $15-20$ & $20-25$ & $>25$ & \\
\hline Female & $23(23)$ & $22(22)$ & $35(35)$ & $9(9)$ & 0 & $12(12)$ & 101 \\
\hline Male & $42(21)$ & $47(24)$ & $56(28)$ & $26(13)$ & $5(3)$ & $23(12)$ & 199 \\
\hline Total & $65(21.66)$ & $69(23.00)$ & $91(30.33)$ & $35(11.66)$ & $5(01.66)$ & $35(11.66)$ & $300(100.00)$ \\
\hline
\end{tabular}

Note: Figures within the parenthesis indicate the percentage of respondents and the figures outside represent the number.

Table 3. Cross tabulation between work experience and acclimatization period

\begin{tabular}{|c|c|c|c|c|c|c|c|}
\hline \multirow{2}{*}{$\underset{\text { (years) }}{\text { Work experience }}$} & \multicolumn{6}{|c|}{ Acclimatization period (in days) } & \multirow{2}{*}{ Total } \\
\hline & $<5$ & $5-10$ & $10-15$ & $15-20$ & $20-25$ & $>25$ & \\
\hline$<2$ & $11(22)$ & $10(20)$ & $20(41)$ & $5(10)$ & $1(2)$ & $2(4)$ & $49(16.33)$ \\
\hline $2-5$ & $15(24)$ & $18(29)$ & $17(27)$ & $7(11)$ & $2(3)$ & $3(5)$ & $62(20.66)$ \\
\hline $6-10$ & $24(18)$ & $26(20)$ & $42(32)$ & $16(12)$ & $2(2)$ & $20(15)$ & $130(43.33)$ \\
\hline $11-14$ & $13(25)$ & $14(27)$ & $10(20)$ & $5(10)$ & 0 & $9(18)$ & $51(17.00)$ \\
\hline$>14$ & $2(25)$ & $1(12.5)$ & $2(25)$ & $2(25)$ & 0 & $1(12.5)$ & $8(02.66)$ \\
\hline Total & $65(21.66)$ & $69(23.00)$ & $91(30.33)$ & $35(11.66)$ & $5(01.66)$ & $35(11.66)$ & $300(100.00)$ \\
\hline \multicolumn{8}{|c|}{ Chi-square $=52.178, p<0.05$} \\
\hline
\end{tabular}

Note: Figures within the parenthesis indicate the percentage of respondents and the figures outside represent the number. 
er the number of days the expatriates need for acclimatization in the host country. Majority of the respondents (43.33\%) have a work experience between 6 and 10 years and out of which a majority of them needed just 10-15 days for acclimatization. This can be attributed to their long stint of work experience, and their prior exposure to the international assignments in different countries.

In Table 3 the association between the work experience of employees and the acclimatization period needed for the respondents in host country can be explained. The findings from the above table reveal that there is a statistically significant association between the work experience of expatriates and their acclimatization period [ $p$-value $(0.000)<0.05]$. This significant association can be attributed to the fact that the respondents with relatively higher work experience will have better exposure, coping mechanisms and hence are less likely to become vulnerable to cultural shocks. On the other hand, the respondents with relatively lesser work experience may not have adequate exposure, experience and coping methods to deal with the cultural shocks during their acclimatization process. Hence, Hypothesis 2 is rejected.

This is in line with the findings of a study by Shaffer et al. (1999) who found that the expatriates who were well experienced in their job roles were able to adjust better to international projects. Thus, according to the findings and the existing literature, it can be concluded that work experience has a significant influence on the rate at which expatriates adjust to the host country work conditions.

H3: The acclimatization of expatriates in the host country is significantly influenced by the area of work.

The study intended to examine whether the expatriate's area of work played an important role in influencing their adjustment to overseas work- place. In order to study this, the study included people working in five different departments of the IT industry, namely, finance, hardware, human resources, operations and software. Table 4 presents the relationship between area of work and acclimatization of expatriates in the host country. The results revealed that area of work played a tangible role in improving the acclimatization level of the expatriates, albeit it could only explain $5.3 \%$ of the variation in the acclimatization $(F=16.548, \beta=0.241, p=0.000)$. This implies that there are various other factors which contribute to the acclimatization level of the expatriates, for example, motivation, nonfinancial rewards, etc. However, as the role of area of work had a significant impact, Hypothesis 3 is accepted.

This finding is in agreement with the observations made by Bhanugopan and Fish (2004) who found that the kind of job role and work responsibilities shouldered by expatriates, impact the extent of acclimatization. Therefore, on the basis of the findings of the present study and the observations made in previous research, it can be concluded that the area of the expatriates' work exerts significant influence on the rate of their acclimatization.

H4: The acclimatization of expatriates in the host country is significantly influenced by the length of assignment.

With regard to length of assignments, the study included people whose assignments in the host countries last from less than six months to more than 2 years. The relationship between length of assignment and acclimatization of expatriates in the host country has been presented in Table 5. Length of expatriate assignment was found to be directly related to acclimatization, although the explained variance is small. Furthermore, it is evident from the results that there is a weak rela-

Table 4. Impact of area of work on acclimatization of expatriates

\begin{tabular}{|c|c|c|c|c|c|c|}
\hline \multirow{2}{*}{\multicolumn{2}{|c|}{ Model }} & \multicolumn{2}{|c|}{ Unstandardized coefficients } & \multirow{2}{*}{$\begin{array}{c}\begin{array}{c}\text { Standardized } \\
\text { coefficients }\end{array} \\
\text { Beta }\end{array}$} & \multirow[t]{2}{*}{$\mathbf{t}$} & \multirow[t]{2}{*}{ Sig. } \\
\hline & & B & Std. error & & & \\
\hline \multirow{2}{*}{1} & Constant & 2.952 & 0.239 & - & 12.353 & 0.000 \\
\hline & Area of work & 0.241 & 0.059 & 0.229 & 4.068 & 0.000 \\
\hline
\end{tabular}

Note: $R^{2}=0.053, F=16.548, p<0.01$. 
Table 5. Impact of length of assignment on acclimatization of expatriates

\begin{tabular}{|c|c|c|c|c|c|c|}
\hline & \multirow{2}{*}{ Model } & \multicolumn{2}{|c|}{ Unstandardized coefficients } & \multirow{2}{*}{$\begin{array}{c}\begin{array}{c}\text { Standardized } \\
\text { coefficients }\end{array} \\
\text { Beta } \\
\end{array}$} & \multirow[t]{2}{*}{$\mathbf{t}$} & \multirow{2}{*}{ Sig. } \\
\hline & & B & Std. error & & & \\
\hline \multirow{2}{*}{1} & Constant & 3.195 & 0.228 & - & 13.996 & 0.000 \\
\hline & Length of assignment & 0.184 & 0.057 & 0.184 & 3.229 & 0.001 \\
\hline
\end{tabular}

Note: $R^{2}=0.034, F=10.426, p<0.01$.

Table 6. Impact of career support practices on acclimatization of expatriates

\begin{tabular}{|c|c|c|c|c|c|c|}
\hline & \multirow{2}{*}{ Model } & \multicolumn{2}{|c|}{$\begin{array}{c}\text { Unstandardized } \\
\text { coefficients }\end{array}$} & \multirow{2}{*}{$\begin{array}{c}\begin{array}{c}\text { Standardized } \\
\text { coefficients }\end{array} \\
\text { Beta } \\
\end{array}$} & \multirow[t]{2}{*}{$\mathbf{t}$} & \multirow{2}{*}{ Sig. } \\
\hline & & B & Std. error & & & \\
\hline \multirow{2}{*}{1} & Constant & 3.159 & 0.266 & - & 11.881 & 0.000 \\
\hline & Career Support Practices & 0.162 & 0.063 & 0.148 & 2.582 & 0.010 \\
\hline
\end{tabular}

Note: $R^{2}=0.022, F=6.667, p<0.01$.

tionship between the two, as only $3.4 \%$ of the variation in the acclimatization period of expatriates could be explained by the assignment duration. However, this result was significant with $F$ value of 10.426. Therefore, Hypothesis 4 is accepted.

The above results are indirectly supported by a study by Downes et al. (2000) who found that the duration of overseas assignment plays an important role in the job satisfaction of expatriates. This can be extended further to imply that duration or length of assignment results in job satisfaction, which would help the expatriates to adjust to the job better. This is a clear indication that the length of overseas assignment indeed plays a major role in ensuring the expatriates' acclimatization.

H5: Career support practices have a positive influence on acclimatization of expatriates.

The career support practices included 8 parameters, which are, meeting job performance objectives of the host country firm; participation in designing and implementing the organizational goals of the host country firm; communication of formal tasks by the top management through proper channels; meeting specific job responsibilities of the host country firm; interacting with host country co-workers and promoting positive workplace relationships; forming relationships with the business clients of the host country; adopting to the business customs and norms of the host country firm, and the capacity of the HR department to provide necessary skills and training to perform the job well.
The relationship between the career support practices and acclimatization of expatriates is discussed in Table 6. The results from the above table indicate that there is a weak relationship, as only $2.2 \%$ of the expatriate acclimatization is due to career support practices. However, as this result was significant with an $F$ value of 6.667, Hypothesis 5 is accepted.

There are a number of empirical studies which propose that the career support services prevailing in and implemented by MNCs will have a significant impact on the performance of the expatriates (van der Heijden, van Engen, \& Paauwe, 2009), which in turn may result in a greater desire to remain with the organization upon repatriation (Lazarova \& Caligiuri, 2001). The above results are in agreement with the findings of Pires et al. (2006) who points out that providing detailed cross-country training and orientation program along with an introduction to the expatriate network in the host country will help expatriates and their families to adjust to the foreign country with minimal cultural shock resulting in effective discharge of duties.

Thus, on the basis of the findings of the present study and previous researches, it can be said that career support services provided by the organization will definitely influence the expatriate adjustment to the host country culture which in turn optimizes their on-job performance. Moreover, it can also be said that perceived career support leads to increased loyalty, commitment and efficiency. Thus, the present study concludes that career support practices influence the expatriate acclimatization positively. 


\section{CONCLUSION AND SUGGESTIONS}

The current study aimed at understanding the acclimatization period of expatriates, which is very important for the multinational corporations to facilitate their adjustment process. The influence of selected contextual variables such as career support practices, length of assignment, and area of work was analyzed. The data were collected through a structured questionnaire from 300 expatriates working in 50 IT companies in Bangalore.

The linear regression results confirm the basic notion endorsed by Stahl et al. (2009), Lazirova and Caliguiri (2001), that acclimatization of expatriates is influenced by the host country work culture and career support practices. However, according to the present study, the relationship between acclimatization of expatriates and work culture, as well as career support practices is weak. This indicates that there are other factors that facilitate the acclimatization of expatriates leading to the smooth functioning of the departments. Therefore, the following suggestions are made on the basis of existing literature and the findings of this study, regarding reducing the time taken by the expatriates to acclimatize with the host country.

Firstly, the present study opines that the cultural acceptances plays a major role in expatriate acclimatization as it would lead to access of more resources with the locals willing to help the expatriates. This suggestion is in line with the findings of a study by Friedman et al (2009) where in it was found that when an expatriate accepts the cultural norms of the host country, the local co-workers and mentors will readily offer assistance, which can help the expatriate to understand and accept the culture. Therefore, cultural acceptance and expatriate acclimatization haven effectively cyclical relationship. Thus, the study suggests that helping the expatriates to accept the work culture of the host country firm can help in improving the rate of successful expatriate acclimatization.

Secondly, the study suggests that if a company has limited resources for providing expatriate supporting practices, individuals with an inbuilt personal ability to connect and work with people from different cultures can be selected for assignments, as these individuals are less likely to exchange their ideas with the company and have less expectation on expatriate supporting practices. Expatriates who are functionally fit, i.e., able to carry out their regular work-related and personal activities with ease, will gain a broader perception of the host country's culture, will be able to communicate better with the locals thus will be able to carry out the duties and responsibilities in a better manner. It is therefore suggested that the expatriate managers provide their international assignees a work environment, which exposes them to the cultural aspects of the country, thereby helping them adjust better and faster.

\section{CONTRIBUTION OF THE STUDY}

The present article makes significant contributions to the existing body of literature on expatriate management by focusing on emerging multinational companies that offer IT services. The study offers more meaningful insights on expatriate management in relation to organization-related factors such as career support practices, area of work and length of assignment that directly influence work adjustment. One of the important contributions of the study is the observation that gender does not play a role in expatriate acclimatization. The existence of a direct relationship between area of work and length of assignment with expatriate acclimatization period is another unique contribution of the study. Further, the study's focus on acclimatization of expatriates represents a novel value addition to the existing expatriate research literature. 


\section{LIMITATIONS AND SCOPE FOR FURTHER RESEARCH}

The limitations of the present study are described below:

1. The study was limited to IT industry.

2. The geographical area covered by the study was limited to Bangalore city.

3. The study sample had only 300 respondents.

Based on the extensive review of literature and the findings of the study, the following topics were proposed for further research for the enhancement of knowledge in the field of expatriate management in MNCs:

1. Studies that focus on expatriate acclimatization along with factors such as organizational citizenship behavior, job satisfaction, etc., which might help to offer further insights in this current area of investigation.

2. Further research on expatriates can be carried out on other industries located in various other geographical areas for the better understanding of expatriate management.

\section{REFERENCES}

1. Bhanugopan, R., \& Fish, A. (2004). An Empirical Investigation of Job Burnout Among Expatriates. Personnel Review, 35(4), 449-468. https://doi. org/10.1108/00483480610670607

2. Bhaskar-Shrinivas, P., Harrison, D., Shaffer, M. A., \& Luk, D. M. (2005). Input-Based and Time-Based Models of International Adjustment: Meta-Analytic Evidence and Theoretical Extensions. Academy of Management Journal, 48(2), 257-81. https://doi.org/10.5465/ amj.2005.16928400

3. Bonache, J. (2005). Job Satisfaction Among Expatriates, Repatriates and Domestic Employees: The Perceived Impact of International Assignments on Work-related Variables. Personnel review, 34(1), 110-124. https://doi. org/10.1108/00483480510571905

4. Cleveland, H., Mangone, G. J., \& Adams, J. C. (1960). The Overseas Americans. New York: Arno Press.

5. Carpenter, M., Sanders, W., \& Gregersen, H. (2001). Bundling Human Capital with Organizational Context: The Impact of International Assignment Experience on
Multinational Firm Performance and CEO Pay. Academy of Management Journal, 44, 493-511. https://doi.org/10.2307/3069366

6. Cendant (2001). International Assignment Policies and Practices Survey: Asia Pacific. Hong Kong: Cendant International Assignment Services.

7. DeLollis, B. (2007, October 16). International Business Assignments Getting Shorter: More Posts Are Less Than a Year. USA Today, B8.

8. Downes, M., Thomas, Anisya S., Singley, Rodger, B. (2002). Predicting Expatriate Job Satisfaction: The Role of Firm Internationalization. Career Development International, 7(1), 24-36. https://doi. org/10.1108/13620430210414847

9. Edstromn, A., \& Galbraith, J. R. (1977). Transfer of Managers as a Coordinative and Control Strategy in Multinational Organizations. Administrative Science Quarterly, 22, 248-263.

10. Erbacher, D., D'Netto, B., \& Espana, J. (September, 2006). Expatriate Success in China: Impact of Personal and Situational Factors. The Journal of American
Academy of Business, Cambridge, $9(2)$.

11. Friedman, P. A., Dyke, L. S., \& Murphy, S. A. (2009). Expatriate Adjustment from the Inside Out: An Autoethnographic Account. The International Journal of Human Resource Management, 20(2), 252-268.

12. Gupta, A. (2012). International Assignments, Expatriate Adjustment and Perceived Impact of Parent Organization Support. The Business \& Management Review, 3(1), 57.

13. Hays, R. D. (1974). Expatriate Selection: Insuring Success and Avoiding Failure. Journal of International Business Studies, 5, 25-37.

14. Hawley, K. (2009). Developing Your Global Workforce: Expatriate Management in Africa - Not So Easy; No Room for Complacency. HRM Magazine.

15. Kittler, M. G., Rygl, D., Mackinnon, A., \& Wiedemann, K. (2011). Work role and work adjustment in emerging markets: A study of German expatriates in CEE countries and Russia. Cross Cultural Management: An International Journal, 
18(2), 165-184. https://doi. org/10.1108/13527601111126003

16. Kobrin, S. (1988). Expatriate Reduction and Strategic Control in American Multinational Corporations. Human Resource Management, 27, 63-75.

17. Meriläinen, T. (2008). Intercultural Adjustment Challenges in China: The Case of Finnish Expatriates.

18. Moulik, S. R., \& Mazumdar, S. (2012). Expatriate Satisfaction in International Assignments: Perspectives from Indian IT Professionals Working in the US. International Journal of Human Resource Studies, 2(3), 59-79.

19. Pires, G., Stanton, J., \& Ostenfeld, S. (2006). Improving expatriate adjustment and effectiveness in ethnically diverse countries: marketing insights. Cross Cultural Management: An International Journal, 13(2), 156-170.

20. Reiche, B. S., Kraimer, M. L., \& Harzing, A-W. (2011). Why do International Assignees Stay? An Organizational Embeddedness Perspective. Journal of International Business Studies, 42(4), 521-544. Retrieved from https://link.springer.com/article/10.1057/jibs.2011.5

21. Ronen, S. (1986). Comparative and Multinational Management (4th ed.). New York, John Wiley and Sons.
22. Sanchez, J. I., Spector, P. E., \& Cooper, C. L. (2000). Adapting to a Boundary less World: A Development Expatriate Model. Academy of Management Executive, 14, 96-107.

23. Selmer, J. (2002). Practice makes perfect? International experience and expatriate adjustment. MIR: Management International Review, 71-87.

24. Shaffer, M., Harrison, D., \& Gilley, K. (1999). Dimensions, Determinants and Differences in Expatriate Adjustment Process. Journal of International Business Studies, 30(3), 557-581.

25. Shaffer, M., Harrison, D., Gregersen, H., Black, J., \& Ferzandi, L. (2006). You Can Take It with You: Individual Differences and Expatriate Effectiveness. Journal of Applied Psychology, 91(1), 109-125.

26. Stroh, L. K., Gregersen, H. B., \& Black, J. S. (2000). Triumphs and Tragedies, Expectations and Commitments upon Repatriation. The International Journal of Human Resource Management, 11, 681-697.

27. Vogel, Adolf Johan, Jansen Van Vuuren, \& Solly M. Millard (2008). Preparation, Support and Training Requirements of South African Expatriates, South African. Journal of Business Management, 39(3), 33-40.
28. Van der Heijden, J. A., van Engen, M. L., \& Paauwe, J. (2009). Expatriate career support: Predicting expatriate turnover and performance. The international journal of human resource management, 20(4), 831-845.

29. Lazarova, M., \& Caligiuri, P. (2001). Retaining repatriates: The role of organizational support practices. Journal of world business, 36(4), 389-401.

30. Green, T. K. (2005). Work culture and discrimination. California Law Review, 93(3), 623. Retrieved from https://pdfs.semanticscholar. org/25fb/db412ad4915e359623e71 358c678ed3023ac.pdf

31. Van der Heijden, J. A., van Engen, M. L., \& Paauwe, J. (2009). Expatriate career support: Predicting expatriate turnover and performance. The international journal of human resource management, 20(4), 831-845.

32. Lazarova, M., \& Caligiuri, P. (2001). Retaining repatriates: The role of organizational support practices. Journal of world business, 36(4), 389-401.

33. Stahl, G. K., Chua, C. H., Caligiuri, P., Cerdin, J. L., \& Taniguchi, M. (2009). Predictors of turnover intentions in learning-driven and demand-driven international assignments: The role of repatriation concerns, satisfaction with company support, and perceived career advancement opportunities. Human Resource Management, 48(1), 89-109. 